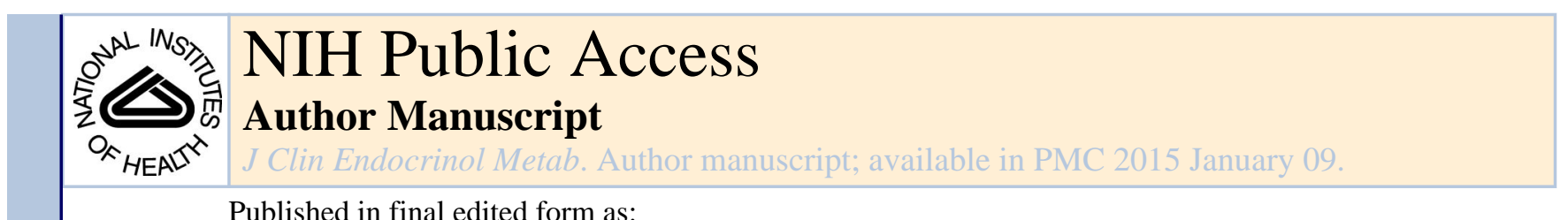

Published in final edited form as:

J Clin Endocrinol Metab. 2007 September ; 92(9): 3517-3522. doi:10.1210/jc.2007-0718.

\title{
Maternal Vitamin D Deficiency Increases the Risk of Preeclampsia
}

\author{
Lisa M. Bodnar, Janet M. Catov, Hyagriv N. Simhan, Michael F. Holick, Robert W. Powers, \\ and James M. Roberts \\ Department of Epidemiology (L.M.B., J.M.C., J.M.R.), University of Pittsburgh Graduate School of \\ Public Health, Pittsburgh, Pennsylvania 15261; Department of Obstetrics, Gynecology, and \\ Reproductive Sciences (L.M.B., J.M.C., H.N.S., R.W.P., J.M.R.), University of Pittsburgh School \\ of Medicine, Pittsburgh, Pennsylvania 15261; Magee-Womens Research Institute (L.M.B., J.M.C., \\ H.N.S., R.W.P., J.M.R.), Pittsburgh, Pennsylvania 15213; and Vitamin D Laboratory (M.F.H.), \\ Section of Endocrinology, Nutrition and Diabetes, Department of Medicine, Boston University \\ School of Medicine, Boston, Massachusetts 02115
}

\section{Abstract}

Context-Vitamin D has direct influence on molecular pathways proposed to be important in the pathogenesis of preeclampsia, yet the vitamin D-preeclampsia relation has not been studied.

Objectives-We aimed to assess the effect of maternal 25-hydroxyvitamin D [25(OH)D] concentration on the risk of preeclampsia and to assess the vitamin D status of newborns of preeclamptic mothers.

Design and Setting-We conducted a nested case-control study of pregnant women followed from less than 16 wk gestation to delivery (1997-2001) at prenatal clinics and private practices.

Patients-Patients included nulliparous pregnant women with singleton pregnancies who developed preeclampsia $(n=55)$ or did not develop preeclampsia $(n=219)$. Women's banked sera were newly measured for $25(\mathrm{OH}) \mathrm{D}$.

Main Outcome Measure-The main outcome measure was preeclampsia (new-onset gestational hypertension and proteinuria for the first time after $20 \mathrm{wk}$ gestation). Our hypotheses were formulated before data collection.

Results-Adjusted serum 25(OH)D concentrations in early pregnancy were lower in women who subsequently developed preeclampsia compared with controls [geometric mean, $45.4 \mathrm{nmol} /$ liter, and 95\% confidence interval (CI), 38.6 -53.4 nmol/liter, vs. 53.1 and $47.1-59.9 \mathrm{nmol} / \mathrm{liter} ; P$ $<0.01]$. There was a monotonic dose-response relation between serum $25(\mathrm{OH}) \mathrm{D}$ concentrations at less than $22 \mathrm{wk}$ and risk of preeclampsia. After confounder adjustment, a 50-nmol/liter decline in $25(\mathrm{OH}) \mathrm{D}$ concentration doubled the risk of preeclampsia (adjusted odds ratio, 2.4; 95\% CI, 1.1-

Copyright (C) 2007 by The Endocrine Society

Address all correspondence and requests for reprints to: Lisa M. Bodnar, Ph.D., M.P.H., R.D., Department of Epidemiology, University of Pittsburgh Graduate School of Public Health, A742 Crabtree Hall, 130 DeSoto Street, Pittsburgh, Pennsylvania, 15261. bodnar@edc.pitt.edu.

Disclosure Statement: L.M.B., J.M.C., H.N.S., R.W.P., and J.M.R. have nothing to declare. M.F.H. received funds from Quest Diagnostics, Merck, Novartis, and Proctor \& Gamble. 
5.4). Newborns of preeclamptic mothers were twice as likely as control newborns to have 25(OH)D less than $37.5 \mathrm{nmol} / \mathrm{liter}$ (adjusted odds ratio, 2.2; 95\% CI, 1.2- 4.1).

Conclusions-Maternal vitamin D deficiency may be an independent risk factor for preeclampsia. Vitamin D supplementation in early pregnancy should be explored for preventing preeclampsia and promoting neonatal well-being.

MATERNAL VITAMIN D deficiency is a widespread public health problem. In a recent study, we found that approximately $29 \%$ of Black pregnant women and $5 \%$ of white pregnant women residing in the northeastern United States had vitamin D deficiency, i.e. serum 25-hydroxyvitamin D [25(OH)D] of less than $37.5 \mathrm{nmol} /$ liter, whereas $54 \%$ of Black women and $47 \%$ of white women had serum $25(\mathrm{OH}) \mathrm{D}$ levels indicative of vitamin D insufficiency, i.e. $25(\mathrm{OH}) \mathrm{D}$ of $37.5-80 \mathrm{nmol} / \mathrm{liter}(1)$. These staggeringly high rates of poor maternal vitamin $\mathrm{D}$ status, particularly among those with deeply pigmented skin, are also found in other regions throughout the world (2-6). The vitamin D deficiency epidemic during pregnancy is caused by a lack of adequate sunlight exposure needed to synthesize vitamin $\mathrm{D}_{3}$ (cholecalciferol) in the skin, coupled with oral intakes that are too low to meet the increased demands of pregnancy, even with regular use of prenatal vitamins containing 400 IU vitamin $\mathrm{D}_{3}(1,6,7)$.

Vitamin D deficiency during pregnancy has been linked with a number of serious short- and long-term health problems in offspring, including impaired growth, skeletal problems, type 1 diabetes, asthma, and schizophrenia (8). Yet few investigators have explored the role of maternal vitamin D status in adverse pregnancy outcomes. Preeclampsia is a pregnancyspecific syndrome that affects approximately $3-7 \%$ of first pregnancies. The known racial disparity in preeclampsia, with Black women being more likely to develop severe preeclampsia and suffer greater morbidity associated with the disorder than white women ( 9 , 10), suggests vitamin D may be relevant. Moreover, the pathogenesis of preeclampsia involves a number of biological processes that may be directly or indirectly affected by vitamin $\mathrm{D}$, including immune dysfunction, placental implantation, abnormal angiogenesis, excessive inflammation, and hypertension (11-14). Vitamin D has been hypothesized to influence preeclampsia risk (15), but we are unaware of any original reports examining the relation between maternal vitamin D status before the clinical onset of preeclampsia and the risk of disease.

Our objectives were 2-fold. First, we sought to assess the independent effect of maternal $25(\mathrm{OH}) \mathrm{D}$ levels in early pregnancy on the risk of preeclampsia. Second, we aimed to assess the vitamin D status of fetuses of preeclamptic mothers.

\section{Patients and Methods}

For this analysis, we used data and banked sera collected from women and newborns in 1997-2001 and completed 25(OH)D assays on the banked sera in 2006 to answer our aforementioned research questions. Data came from the Pregnancy Exposures and Preeclampsia Prevention Study, a prospective cohort study designed to examine factors that predispose women to preeclampsia. Women were enrolled at less than $16 \mathrm{wk}$ gestation from outpatient clinics at Magee-Womens Hospital in Pittsburgh, PA, and affiliated private 
practices from 1997-2001. Women aged 14-44 yr, carrying singleton infants, and planning to deliver at Magee-Womens Hospital were eligible. The response rate was $72 \%$. After providing informed, written consent, all subjects completed an interviewer-administered questionnaire at enrollment to collect data on sociodemographics, medical history, and health behaviors. Nonfasting blood samples were collected at times of usual phlebotomy for clinical indications and stored at $-80 \mathrm{C}$. Medical records were abstracted to ascertain blood pressures and urinary protein measurements throughout gestation, use of antihypertensive medications, antepartum and delivery events, and neonatal outcomes. Venous umbilical cord blood samples were collected, and serum was processed and stored at $-80 \mathrm{C}$. The study was approved by the University of Pittsburgh Review Board.

A total of 2211 women enrolled in the study and had complete data on pregnancy outcomes. We conducted a nested case-control study among the 1198 women in the cohort who were nulliparous (i.e. the index pregnancy was their first delivery) and had no preexisting medical conditions (e.g. pregestational diabetes mellitus or chronic hypertension). We selected nulliparous women because the etiology of preeclampsia may differ by parity (16). There were 59 preeclampsia cases in the cohort (4.9\% incidence). Of these, 55 cases had at least one blood sample banked and were therefore included in the current analysis. We randomly selected 220 non-preeclamptic women in the cohort to serve as controls. We did not match on any covariates because matching on factors that are not true confounders can reduce efficiency and introduce bias.

From each of the 55 cases and 220 controls, we sought to select one serum sample at less than $22 \mathrm{wk}$ gestation, one predelivery serum sample, and a cord serum sample. If a woman had more than one sample collected at less than $22 \mathrm{wk}$ gestation, we randomly selected one sample using a random number generator. We chose $22 \mathrm{wk}$ as the cutoff point because it generally precedes the clinical onset of disease. One of the controls had one sample available that measured more than $300 \mathrm{nmol} /$ liter. As described below, it was excluded because it was outside of the detectable range, leaving 219 controls. Of the 55 cases, 49 had an available banked serum sample collected at less than $22 \mathrm{wk}, 38$ had an available banked serum sample collected predelivery, and 40 had an available banked cord serum sample. These numbers were 216, 189, and 164 for the 219 controls, respectively.

\section{Quantitation of serum 25(OH)D}

Maternal and cord serum samples were stored from 1997-2001 in aliquots at $-80 \mathrm{C}$ until assay in 2006. Quantitation of serum $25(\mathrm{OH}) \mathrm{D}\left[25(\mathrm{OH}) \mathrm{D}_{2}\right.$ plus $\left.25(\mathrm{OH}) \mathrm{D}_{3}\right]$ was performed using a commercial ELISA from Immunodiagnostic Systems Limited (IDS, Tyne, UK) and validated against a HPLC method in the laboratory of Dr. James Roberts at the MageeWomens Research Institute. The ELISA could detect 25(OH)D in the range of 5-300 nmol/ liter. Three samples were more than $300 \mathrm{nmol} /$ liter and were excluded from this analysis. No samples in our analysis fell below the detectable range. The interassay coefficient of variation for the ELISA was $10.3 \%$. The ELISA recognized $100 \%$ of $25(\mathrm{OH}) \mathrm{D}_{3}$ and $75 \%$ of $25(\mathrm{OH}) \mathrm{D}_{2}$ but did not distinguish between these two forms. In our initial HPLC validation, we observed that only three of 32 samples $(<10 \%)$ had any measurable $25(\mathrm{OH}) \mathrm{D}_{2}$, and within these samples, $25(\mathrm{OH}) \mathrm{D}_{2}$ accounted for only $10 \%$ of the total measurable $25(\mathrm{OH}) \mathrm{D}$. 
Details describing our method for validating the results of the ELISA against HPLC were described in detail previously (1). The interassay coefficient of variation for $25(\mathrm{OH}) \mathrm{D}_{3}$ using the HPLC method was 5.8\%. The sensitivity of the HPLC method was $<10 \mathrm{nmol} / \mathrm{liter}$ and had a linear range to $1000 \mathrm{nmol} / \mathrm{liter}$. The relationship between serum 25(OH)D concentrations obtained from the ELISA compared with HPLC was as follows: slope $=1.14$, intercept $=22$, and $r=0.88$. Because the ELISA overestimated concentrations of 25(OH)D by $25 \%$ throughout the standard curve, we adjusted the values obtained by ELISA so they would be in better agreement with data obtained by HPLC.

Because there is no universally acceptable definition of vitamin D deficiency, we used cutoff points suggested recently $(8,17)$. The same cutoffs were used for both women and neonates because the definition of vitamin D sufficiency does not vary by age (8).

Preeclampsia was defined as gestational hypertension and proteinuria and return of all abnormalities to normal by $12 \mathrm{wk}$ postpartum (18). Gestational hypertension was defined as systolic blood pressure persistently $140 \mathrm{~mm} \mathrm{Hg}$ or higher and/or diastolic blood pressure persistently $90 \mathrm{~mm} \mathrm{Hg}$ or higher for the first time after $20 \mathrm{wk}$ gestation. We determined blood pressure as the average of the last five pressures obtained after hospital admission for delivery before medications or clinical perturbations that would alter blood pressure. Proteinuria was defined as the excretion of more than $300 \mathrm{mg}$ protein in $24 \mathrm{~h}$, a random sample of $2+$ protein, a catheterized sample of $1+$ protein, or a protein-creatinine ratio more than 0.3. A jury of clinical experts reviewed medical records of all women in the cohort to assign preeclampsia diagnoses.

Race/ethnicity was self-reported as non-Hispanic white or non-Hispanic Black. Season of sample collection was defined as winter (December, January, and February), spring (March, April, and May), summer (June, July, and August), and fall (September, October, and November). Prepregnancy body mass index (BMI) (weight in kilograms divided by height in square meters) was based on measured height and maternal self-report of prepregnancy weight at the initial visit. Self-reported data were available on gravidity (i.e. number of times a woman has been pregnant: one, two, or three or more), marital status (married or unmarried), maternal education $(<12,12$, or $>12 \mathrm{yr})$, and smoking status in the year before the index pregnancy (smoker or nonsmoker). At enrollment, women were asked to report whether they used multivitamins or prenatal vitamins at least once per week in the periconceptional period (defined as the 3 months before and 3 months after conception). Women were also asked to categorize their usual amount of time spent watching television in the year before the index pregnancy as $0-10,11-20,21-30$, or more than $30 \mathrm{~h} / \mathrm{wk}$. Women were asked whether they engaged in any leisure-time physical activity in the year before the index pregnancy and, if so, to rate the usual intensity of this activity as low, medium, or high.

\section{Statistical analysis}

Serum 25(OH)D concentrations were log-transformed before statistical tests were performed. We used Pearson $\chi^{2}$ statistics to compare proportions of women or neonates with vitamin D deficiency by case status. Spearman's rank correlation coefficient was used to test for correlations between maternal and cord serum 25(OH)D levels. Multivariable linear 
regression was used to estimate differences in mean $25(\mathrm{OH}) \mathrm{D}$ concentrations by case status after adjustment for confounders. We used multivariable logistic regression to assess the independent effect of maternal early-pregnancy $25(\mathrm{OH}) \mathrm{D}$ concentrations on the risk of preeclampsia. To assess the dose-response relation between 25(OH)D levels and preeclampsia risk, we used published methods (19) to determine the most appropriate specification of $25(\mathrm{OH}) \mathrm{D}$ in our model. We tested numerous spline terms and fractional polynomials, but the best fit was found using serum 25(OH)D as a continuous, linear variable. Finally, multivariable log-binomial regression was used to assess the influence of preeclampsia diagnosis on the risk of vitamin $\mathrm{D}$ deficiency in newborns.

We fit parsimonious regression models by specifying full models with potential effect modifiers and confounding variables: race/ethnicity, maternal age, education, marital status, season, gravidity, maternal prepregnancy BMI, smoking status, periconceptional multivitamin use, television watching, physical activity, and sample gestational age. Effect modification by race was tested using a likelihood ratio test $(a=0.10)$. Potential confounders were considered to not be influential and were removed from the model if their inclusion did not satisfy our a priori change-in-estimate criterion (a >10\% change in the coefficient for linear regression or a $>10 \%$ change in the exponentiated coefficient in logistic and log-binomial regression). Maternal race/ethnicity, sample gestational age, prepregnancy BMI, education, season, and sample gestational age met our definition of confounding and were included in the final models.

An important unmeasured covariate in our dataset was calcium intake. Low calcium intake may be associated with vitamin D deficiency (20) and may be a risk factor for preeclampsia (21). Therefore, calcium intake may confound an association between maternal 25(OH)D and preeclampsia risk. In the absence of calcium data, we used sophisticated methods recently developed by methodologists to control for unmeasured confounding (22). These methods allow investigators to use a known or expected range of effect estimates of the exposure-confounder and confounder-outcome relations to adjust their final model results for the unmeasured covariate. The text describing these methods in detail is published as supplemental data on The Endocrine Society's Journals Online web site at http:// jcem.endojournals.org (39). We compared the odds ratio (OR) and 95\% confidence interval (CI) from the conventional logistic regression model of maternal $25(\mathrm{OH}) \mathrm{D}$ and preeclampsia risk with estimates obtained from the sensitivity analysis iterations, which reflected systematic error and random error associated with missing data on calcium intake (22).

\section{Results}

Cases of preeclampsia were more likely than non-preeclamptic controls to be older, nonHispanic white, married, more educated, nonsmokers, and overweight at the start of pregnancy (Table 1). Serum samples were drawn at similar gestational ages in cases and controls.

Adjusted serum 25(OH)D concentrations in early pregnancy were $15 \%$ lower in women who subsequently developed preeclampsia compared with controls (Table 2). Furthermore, vitamin $\mathrm{D}$ deficiency at less than $22 \mathrm{wk}$ gestation was more common among women who 
later developed preeclampsia than among women who did not develop preeclampsia. Earlypregnancy maternal $25(\mathrm{OH}) \mathrm{D}$ concentration less than $37.5 \mathrm{nmol} /$ liter was associated with a 5-fold increase in the odds of preeclampsia (adjusted OR, 5.0; 95\% CI, 1.7-14.1), independent of race/ethnicity, season, sample gestational age, prepregnancy BMI, and education. These results were only slightly attenuated after accounting for unmeasured confounding by calcium intake (point estimate, 4.6 ; 95\% sensitivity analysis interval, $1.6-$ 13.1). Indeed, as shown in Fig. 1, there was a strong, inverse relation between serum 25(OH)D levels at less than $22 \mathrm{wk}$ and risk of preeclampsia $(P=0.02)$. After adjustment for race/ethnicity, season, sample gestational age, education, and prepregnancy BMI, a 50-nmol/ liter decline in $25(\mathrm{OH}) \mathrm{D}$ concentration more than doubled the risk of preeclampsia (adjusted OR, 2.4; 95\% CI, 1.1-5.4).

At delivery, maternal 25(OH)D concentrations remained $15 \%$ lower in women with overt preeclampsia compared with non-preeclamptic controls (adjusted mean, $54.4 \mathrm{nmol} / \mathrm{liter}$, and $95 \% \mathrm{CI}, 45.1-65.7 \mathrm{nmol} / \mathrm{liter}, v s .64 .7$ and $56.4-74.2 \mathrm{nmol} / \mathrm{liter} ; P=0.05)$. There was a high correlation between maternal predelivery and cord serum $25(\mathrm{OH}) \mathrm{D}$ in cases $(\mathrm{r}=0.97$; $P<0.0001)$ and controls $(\mathrm{r}=0.84 ; P<0.0001)$, and therefore, cord serum $25(\mathrm{OH}) \mathrm{D}$ concentrations were also significantly lower among neonates of preeclamptic mothers than among neonates of non-preeclamptic control mothers (Table 3). Newborns of preeclamptic mothers were twice as likely as newborns of non-preeclamptic mothers to have $25(\mathrm{OH}) \mathrm{D}$ less than $37.5 \mathrm{nmol} /$ liter after controlling for confounders.

None of these associations varied by maternal race/ethnicity.

\section{Discussion}

Our results showed that maternal vitamin D deficiency at less than 22 wk gestation was a strong, independent risk factor for preeclampsia. Importantly, there was a monotonic doseresponse relation between maternal serum $25(\mathrm{OH}) \mathrm{D}$ and risk of preeclampsia. As maternal serum $25(\mathrm{OH}) \mathrm{D}$ concentrations at less than $22 \mathrm{wk}$ increased, the risk of preeclampsia strikingly decreased throughout the $25(\mathrm{OH}) \mathrm{D}$ distribution. Additionally, we observed that neonates born to preeclamptic mothers were significantly more likely to have poor vitamin D status than neonates of control mothers. These differences were found in our population despite widespread prenatal/multivitamin use in the 3 months before delivery (93\%) and in the periconceptional period (46\%).

Small studies have reported reduced maternal serum 25(OH)D in overt preeclampsia (23, 24), which we confirmed in our analysis, but to our knowledge, our study is the first to explore the 25(OH)D-preeclampsia relation before the onset of clinical symptoms. In a recent observational study in Icelandic women, a U-shaped relation between vitamin $\mathrm{D}$ intake at 11-15 wk gestation and the risk of hypertensive disorders was suggested (25), but the authors did not analyze this relation separately for preeclamptics or measure serum 25(OH)D.

Two clinical trials support a potential role of vitamin D in the prevention of preeclampsia, although neither of these treated with vitamin D supplements alone. In an uncontrolled trial, 
supplementation with a multivitamin/mineral supplement and halibut liver oil (containing $900 \mathrm{IU} / \mathrm{d}$ vitamin D) provided at $20 \mathrm{wk}$ gestation reduced the odds of preeclampsia by $32 \%$ (95\% CI, 11-47\%) (26). Marya et al. (27) randomized 400 women at 20-24 wk gestation to vitamin D (1200 IU/d) and calcium $(375 \mathrm{mg} / \mathrm{d})$ supplements or no treatment and found a significant reduction in blood pressure $(P<0.001)$ and a nonsignificant reduction in the incidence of preeclampsia in the treated group compared with the untreated (6vs. 9\%). In a cohort study, investigators found that regular supplementation with vitamin D in the first year of life halved the risk of preeclampsia in the female offspring's first pregnancy (28). Studies of seasonal patterns in preeclampsia show the lowest incidence in summer, when sunlight is plentiful and serum $25(\mathrm{OH}) \mathrm{D}$ concentrations are at their peak, and the highest incidence in winter, when synthesis of vitamin $\mathrm{D}_{3}$ is limited in temperate zones and serum $25(\mathrm{OH}) \mathrm{D}$ levels are at their nadir $(29,30)$.

There are numerous biologically plausible mechanisms by which maternal vitamin D status could alter risk of preeclampsia. Preeclampsia is hypothesized to be a two-stage disorder (31). Stage 1 is reduced placental perfusion, often secondary to abnormal implantation. The poorly perfused placenta is proposed to produce materials that, in an appropriate maternal environment, initiate the ensuing multisystem sequelae (stage 2). These pathophysiological changes are proposed to be secondary to abnormal endothelial function, which is a component of a generalized increase in the inflammatory activation that characterizes normal pregnancy (32). The active form of vitamin $\mathrm{D}, 1,25$-dihydroxyvitamin $\mathrm{D}_{3}$, has been shown to regulate the transcription and function of genes associated with placental invasion, normal implantation, and angiogenesis $(12,33)$. Furthermore, abnormal implantation is proposed to be mediated at least in part by an inappropriate immune response between mother and baby. The immunomodulatory properties of 1,25-dihydroxyvitamin $\mathrm{D}_{3}$ may be relevant in this regard $(13,34)$. Maternal vitamin D deficiency may likewise predispose to the increased inflammatory response (13). Notably, vascular structure and function including vascular compliance, elasticity, and intima media thickness are more favorable among women supplemented with vitamin D (35). Vitamin D deficiency may also elevate blood pressure (14). Finally, the proteinuria of preeclampsia is thought to be mediated by renal vascular endothelial growth factor (VEGF). 1,25-Dihydroxyvitamin $\mathrm{D}_{3}$ has been shown to regulate angiogenic processes through direct effects on VEGF gene transcription (11).

Our results highlight that neonates of preeclamptic mothers are at particularly high risk of vitamin D deficiency. However, these results are not unexpected. The fetus relies entirely on the vitamin D stores of the mother, so if the mother is deficient, so is the fetus $(6,36)$.

Because early-life vitamin D deficiency has been associated with adverse health outcomes in offspring (37), neonates of preeclamptic mothers may be an easily identified group that needs a targeted intervention to improve vitamin D status from birth.

Because Black women experience both a higher risk of severe preeclampsia $(9,10)$ and higher prevalence of vitamin D deficiency (1) than white women, our data linking vitamin D deficiency with preeclampsia risk raises the intriguing possibility that vitamin D may contribute to racial disparities in this adverse pregnancy outcome. We had a small sample of 
Black women with preeclampsia $(n=12)$ and therefore limited power to detect an interaction between $25(\mathrm{OH}) \mathrm{D}$ concentrations and race.

We did not have the resources to measure serum vitamin D-binding protein in our samples. Vitamin D-binding protein increases during gestation, whereas $25(\mathrm{OH}) \mathrm{D}$ remains constant (38). Our findings, which reflect total (free and bound) $25(\mathrm{OH}) \mathrm{D}$, may therefore overestimate the available $25(\mathrm{OH}) \mathrm{D}$ to perform physiological functions. We also lacked data on PTH concentration, which would have provided a functional indicator of vitamin D status. We do not know whether multivitamins used by our subjects contained ergocalciferol (vitamin $\mathrm{D}_{2}$ ) or vitamin $\mathrm{D}_{3}$. Because our assay detected $100 \%$ of $25(\mathrm{OH}) \mathrm{D}_{3}$ and $75 \%$ of $25(\mathrm{OH}) \mathrm{D}_{2}$, it would have underestimated concentrations of $25(\mathrm{OH}) \mathrm{D}$ among women whose primary source of vitamin $\mathrm{D}$ was vitamin $\mathrm{D}_{2}$. Although we employed a sensitivity analysis for unmeasured confounding by calcium intake, the associations we assumed between calcium and the exposure and disease may not apply to our population, and residual confounding bias may exist. Future studies with data on calcium intake and vitamin D status will need to further disentangle the effect of each on preeclampsia risk. Nevertheless, our study had several important strengths, including its prospective design, adjudicated preeclampsia outcome, sensitivity analysis for unmeasured confounding, and HPLC validation of the method to quantify $25(\mathrm{OH}) \mathrm{D}$ concentrations.

Our results suggest that maternal vitamin D insufficiency in early pregnancy is an independent risk factor for preeclampsia. If our results are confirmed by others, they suggest that preeclampsia may be added to the growing list of adverse health consequences of maternal vitamin D deficiency. Vitamin D supplementation in early pregnancy should be explored as a safe and effective means of preventing preeclampsia and promoting neonatal well-being.

\section{Acknowledgments}

We gratefully acknowledge Dr. Timothy L. Lash and Mr. Matthew P. Fox of Boston University School of Public Health for providing the program used to generate the sensitivity analysis results. We thank Dr. Jane Cauley of the University of Pittsburgh for sharing her data relating serum 25(OH)D levels to dietary calcium intake in a local cohort. We also thank Michael Frank, Emily Cooperstein, and Marcia Gallaher for technical assistance.

This work was partially supported by National Institutes of Health (NIH) Grants PPG 2PO1 HD30367, 5MO1 RR00056, and P30 DK046204. L.M.B. was supported by NIH Grant K01 MH074092. H.N.S. was supported by NIH Grants R01 HD041663 and R01 HD052732.

\section{Abbreviations}

$\begin{array}{ll}\text { BMI } & \text { Body mass index } \\ \text { CI } & \text { confidence interval } \\ \text { 25(OH)D } & \text { 25-hydroxyvitamin D } \\ \text { OR } & \text { odds ratio }\end{array}$




\section{References}

1. Bodnar LM, Simhan HN, Powers RW, Frank MP, Cooperstein E, Roberts JM. High prevalence of vitamin D insufficiency in black and white pregnant women residing in the northern United States and their neonates. J Nutr. 2007; 137:447-452. [PubMed: 17237325]

2. Alfaham M, Woodhead S, Pask G, Davies D. Vitamin D deficiency: a concern in pregnant Asian women. Br J Nutr. 1995; 73:881-887. [PubMed: 7632669]

3. Grover SR, Morley R. Vitamin D deficiency in veiled or dark-skinned pregnant women. Med J Aust. 2001; 175:251-252. [PubMed: 11587255]

4. Sachan A, Gupta R, Das V, Agarwal A, Awasthi PK, Bhatia V. High prevalence of vitamin D deficiency among pregnant women and their newborns in northern India. Am J Clin Nutr. 2005; 81:1060-1064. [PubMed: 15883429]

5. van der Meer IM, Karamali NS, Boeke AJP, Lips P, Middelkoop BJC, Verhoeven I, Wuister JD. High prevalence of vitamin D deficiency in pregnant non-Western women in The Hague, Netherlands. Am J Clin Nutr. 2006; 84:350-353. [PubMed: 16895882]

6. Lee JM, Smith JR, Philipp BL, Chen TC, Mathieu J, Holick MF. Vitamin D deficiency in a healthy group of mothers and newborn infants. Clin Pediatr. 2007; 46:42-44.

7. Barger-Lux MJ, Heaney RP, Dowell S, Chen TC, Holick MF. Vitamin D and its major metabolites: serum levels after graded oral dosing in healthy men. Osteoporos Int. 1998; 8:222-230. [PubMed: 9797906]

8. Holick MF. Resurrection of vitamin D deficiency and rickets. J Clin Invest. 2006; 116:2062-2072. [PubMed: 16886050]

9. Eskenazi B, Fenster L, Sidney S. A multivariate analysis of risk factors for preeclampsia. JAMA. 1991; 266:237-241. [PubMed: 2056625]

10. MacKay AP, Berg CJ, Atrash HK. Pregnancy-related mortality from preeclampsia and eclampsia. Obstet Gynecol. 2001; 97:533-538. [PubMed: 11275024]

11. Cardus A, Parisi E, Gallego C, Aldea M, Fernandez E, Valdivielso JM. 1,25-Dihydroxyvitamin D3 stimulates vascular smooth muscle cell proliferation through a VEGF-mediated pathway. Kidney Int. 2006; 69:1377-1384. [PubMed: 16557229]

12. Evans KN, Bulmer JN, Kilby MD, Hewison M. Vitamin D and placental-decidual function. J Soc Gynecol Investig. 2004; 11:263-271.

13. Hewison M. Vitamin D and the immune system. J Endocrinol. 1992; 132:173-175. [PubMed: 1541916]

14. Li YC, Kong J, Wei M, Chen ZF, Liu SQ, Cao LP. 1,25-Dihydroxyvitamin $\mathrm{D}_{3}$ is a negative endocrine regulator of the renin-angiotensin system. J Clin Invest. 2002; 110:229-238. [PubMed: 12122115]

15. Hypponen E. Vitamin D for the prevention of preeclampsia? A hypothesis. Nutr Rev. 2005; 63:225-232. [PubMed: 16121476]

16. Ness RB, Roberts JM. Heterogeneous causes constituting the single syndrome of preeclampsia: a hypothesis and its implications. Am J Obstet Gynecol. 1996; 175:1365-1370. [PubMed: 8942516]

17. Hollis BW. Circulating 25-hydroxyvitamin D levels indicative of vitamin D sufficiency: implications for establishing a new effective dietary intake recommendation for vitamin D. J Nutr. 2005; 135:317-322. [PubMed: 15671234]

18. National High Blood Pressure Education Program Working Group on High Blood Pressure in Pregnancy. Report of the National High Blood Pressure Education Program Working Group on High Blood Pressure in Pregnancy. Am J Obstet Gynecol. 2000; 183:S1-S22.

19. Witte JS, Greenland S. A nested approach to evaluating dose-response and trend. Ann Epidemiol. 1997; 7:188-193. [PubMed: 9141641]

20. Steingrimsdottir L, Gunnarsson O, Indridason OS, Franzson L, Sigurdsson G. Relationship between serum parathyroid hormone levels, vitamin D sufficiency, and calcium intake. JAMA. 2005; 294:2336-2341. [PubMed: 16278362] 
21. Hofmeyr GJ, Atallah AN, Duley L. Calcium supplementation during pregnancy for preventing hypertensive disorders and related problems. Cochrane Database Syst Rev. 2006; 3:CD001059. [PubMed: 16855957]

22. Lash TL, Fink AK. Semi-automated sensitivity analysis to assess systematic errors in observational data. Epidemiology. 2003; 14:451-458. [PubMed: 12843771]

23. Cruikshank DP, Chan GM, Doerrfeld D. Alterations in vitamin D and calcium metabolism with magnesium sulfate treatment of preeclampsia. Am J Obstet Gynecol. 1993; 168:1170-1176. discussion 1176-1177. [PubMed: 8475963]

24. Seely EW, Wood RJ, Brown EM, Graves SW. Lower serum ionized calcium and abnormal calciotropic hormone levels in preeclampsia. J Clin Endocrinol Metab. 1992; 74:1436-1440. [PubMed: 1592891]

25. Olafsdottir AS, Magnusardottir AR, Thorgeirsdottir H, Hauksson A, Skuladottir GV, Steingrimsdottir L. Relationship between dietary intake of cod liver oil in early pregnancy and birthweight. BJOG. 2005; 112:424-429. [PubMed: 15777439]

26. Olsen SF, Secher NJ. A possible preventive effect of low-dose fish oil on early delivery and preeclampsia: indications from a 50-year-old controlled trial. Br J Nutr. 1990; 64:599-609. [PubMed: 2265175]

27. Marya RK, Rathee S, Manrow M. Effect of calcium and vitamin D supplementation on toxaemia of pregnancy. Gynecol Obstet Invest. 1987; 24:38-42. [PubMed: 3623260]

28. Hypponen E, Hartikainen AL, Sovio U, Jarvelin MR, Pouta A. Jan 31 Does vitamin D supplementation in infancy reduce the risk of pre-eclampsia? Eur J Clin Nutr. 2007 [Epub ahead of print] PMID: 17268418.

29. Bodnar LM, Catov JM, Roberts JM. Racial/ethnic differences in the monthly variation of preeclampsia incidence. Am J Obstet Gynecol. 2007; 196:e1-e5. [PubMed: 17403406]

30. Magnus P, Eskild A. Seasonal variation in the occurrence of pre-eclampsia. BJOG. 2001; 108:1116-1119. [PubMed: 11762648]

31. Roberts JM, Gammill HS. Preeclampsia: recent insights. Hypertension. 2005; 46:1243-1249. [PubMed: 16230510]

32. Redman CW, Sacks GP, Sargent IL. Preeclampsia: an excessive maternal inflammatory response to pregnancy. Am J Obstet Gynecol. 1999; 180:499-506. [PubMed: 9988826]

33. Daftary GS, Taylor HS. Endocrine regulation of HOX genes. Endocr Rev. 2006; 27:331-355. [PubMed: 16632680]

34. Muller K, Diamant M, Bendtzen K. Inhibition of production and function of interleukin-6 by 1,25dihydroxyvitamin D3. Immunol Lett. 1991; 28:115-120. [PubMed: 1885209]

35. Braam LA, Hoeks AP, Brouns F, Hamulyak K, Gerichhausen MJ, Vermeer C. Beneficial effects of vitamins $\mathrm{D}$ and $\mathrm{K}$ on the elastic properties of the vessel wall in postmenopausal women: a followup study. Thromb Haemost. 2004; 91:373-380. [PubMed: 14961167]

36. Hollis BW, Pittard WB 3rd. Evaluation of the total fetomaternal vitamin D relationships at term: evidence for racial differences. J Clin Endocrinol Metab. 1984; 59:652-657. [PubMed: 6090493]

37. McGrath J. Does 'imprinting' with low prenatal vitamin D contribute to the risk of various adult disorders? Med Hypotheses. 2001; 56:367-371. [PubMed: 11359362]

38. Bouillon R, Van Assche FA, Van Baelen H, Heyns W, De Moor P. Influence of the vitamin Dbinding protein on the serum concentration of 1,25-dihydroxyvitamin D3. Significance of the free 1,25-dihydroxyvitamin D3 concentration. J Clin Invest. 1981; 67:589-596. [PubMed: 6894152]

39. Flanders WD, Khoury MJ. Indirect assessment of confounding: graphic description and limits on effect of adjusting for covariates. Epidemiology. 1990; 1:239-246. [PubMed: 2081259] 


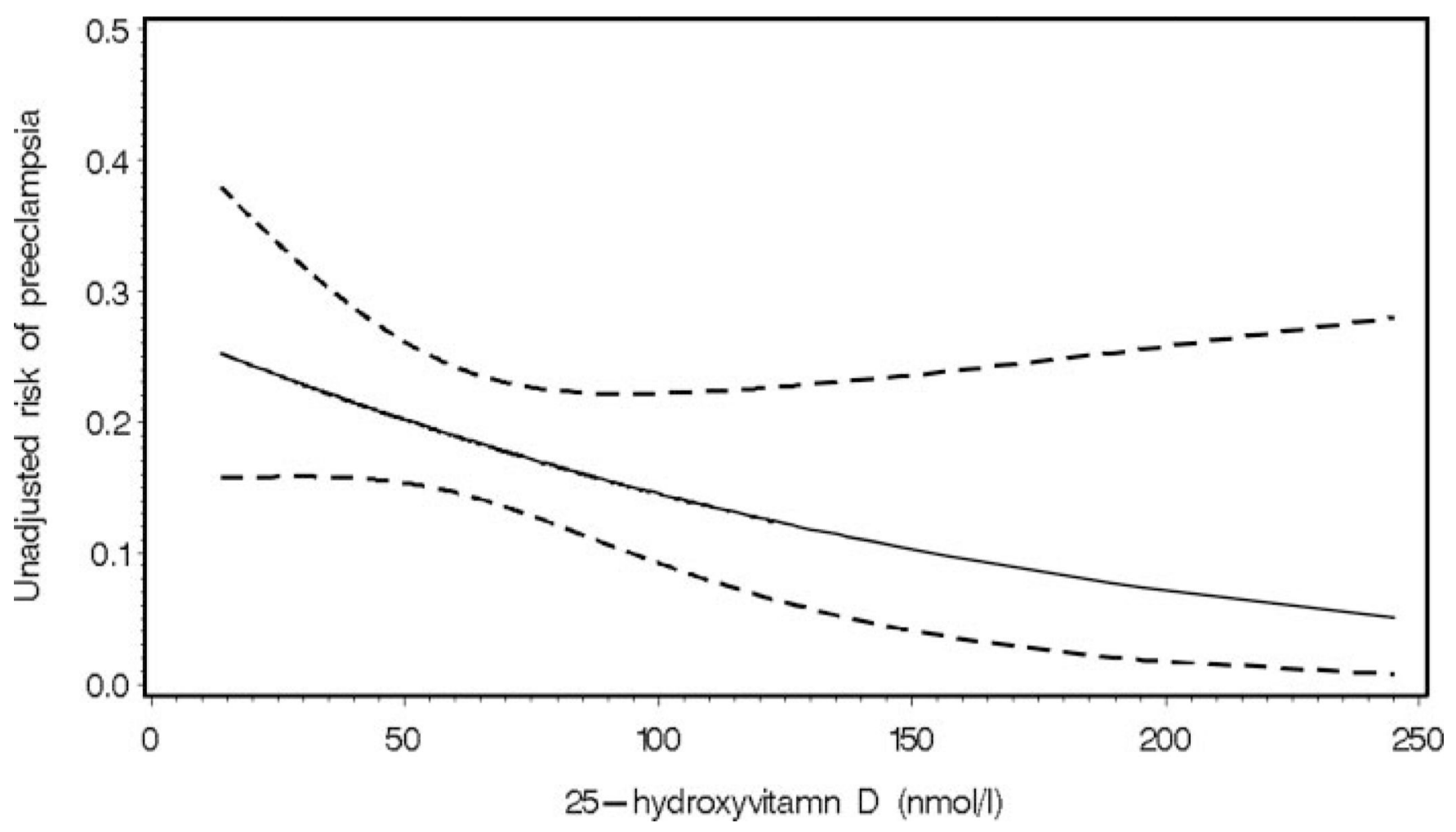

Fig. 1.

Dose-response association between maternal serum 25-hydroxyvitamin D concentration at less than $22 \mathrm{wk}$ gestation and the risk of preeclampsia derived from a logistic regression model $(P=0.02)$. The solid line represents the point estimate, and the dotted lines represent the $95 \%$ confidence bands. 


\section{TABLE 1}

\section{Maternal characteristics}

\begin{tabular}{|c|c|c|}
\hline & $\begin{array}{l}\text { Non-preeclamptic } \\
\text { controls }(n=219)\end{array}$ & $\begin{array}{l}\text { Preeclamptic } \\
\text { cases }(n=55)\end{array}$ \\
\hline \multicolumn{3}{|c|}{ Sociodemographic variables } \\
\hline \multicolumn{3}{|l|}{ Maternal age (\%) } \\
\hline$<20 \mathrm{yr}$ & 37.4 & 20.0 \\
\hline $20-29 \mathrm{yr}$ & 47.5 & 52.7 \\
\hline $30 \mathrm{yr}$ or more & 15.1 & 27.3 \\
\hline \multicolumn{3}{|c|}{ Maternal race/ethnicity (\%) } \\
\hline Non-Hispanic white & 68.5 & 78.2 \\
\hline Non-Hispanic Black & 31.5 & 21.8 \\
\hline \multicolumn{3}{|l|}{ Marital status (\%) } \\
\hline Married & 25.1 & 40.0 \\
\hline Unmarried & 74.9 & 60.0 \\
\hline \multicolumn{3}{|l|}{ Maternal education (\%) } \\
\hline$<12 \mathrm{yr}$ & 25.6 & 12.7 \\
\hline $12 \mathrm{yr}$ & 27.4 & 30.9 \\
\hline$>12 \mathrm{yr}$ & 47.0 & 56.4 \\
\hline \multicolumn{3}{|l|}{ Gravidity $^{a}(\%)$} \\
\hline 1 & 75.3 & 72.7 \\
\hline 2 & 19.2 & 16.4 \\
\hline 3 or more & 5.5 & 10.9 \\
\hline \multicolumn{3}{|l|}{ Lifestyle variables } \\
\hline \multicolumn{3}{|c|}{ Smoking status in the year before the index pregnancy $(\%)$} \\
\hline Smokers & 50.2 & 41.8 \\
\hline Nonsmokers & 49.8 & 58.2 \\
\hline \multicolumn{3}{|l|}{ Prepregnancy BMI (\%) } \\
\hline$<18.5 \mathrm{~kg} / \mathrm{m}^{2}$ & 6.7 & 3.6 \\
\hline $18.5-24.9 \mathrm{~kg} / \mathrm{m}^{2}$ & 50.2 & 38.2 \\
\hline $25.0-29.9 \mathrm{~kg} / \mathrm{m}^{2}$ & 23.3 & 34.6 \\
\hline $230.0 \mathrm{~kg} / \mathrm{m}^{2}$ & 17.8 & 23.6 \\
\hline \multicolumn{3}{|c|}{ Periconceptional $^{b}$ multivitamin use at least once per week (\%) } \\
\hline Yes & 45.7 & 47.3 \\
\hline No & 54.3 & 52.7 \\
\hline \multicolumn{3}{|c|}{ Multivitamin use in the last 3 months of pregnancy (\%) } \\
\hline Yes & 92.5 & 92.5 \\
\hline No & 7.5 & 7.5 \\
\hline \multicolumn{3}{|c|}{ Usual preconceptional television watching (\%) } \\
\hline $0-10 \mathrm{~h} / \mathrm{wk}$ & 43.6 & 38.2 \\
\hline $11-20 \mathrm{~h} / \mathrm{wk}$ & 21.1 & 25.5 \\
\hline $21-30 \mathrm{~h} / \mathrm{wk}$ & 13.3 & 16.4 \\
\hline
\end{tabular}




\begin{tabular}{|c|c|c|}
\hline & $\begin{array}{l}\text { Non-preeclamptic } \\
\text { controls }(n=219)\end{array}$ & $\begin{array}{l}\text { Preeclamptic } \\
\text { cases }(n=55)\end{array}$ \\
\hline$<30 \mathrm{~h} / \mathrm{wk}$ & 22.0 & 20.0 \\
\hline \multicolumn{3}{|l|}{ Preconception leisure-time physical activity (\%) } \\
\hline None & 59.6 & 61.8 \\
\hline Yes, low intensity & 6.0 & 10.9 \\
\hline Yes, medium intensity & 21.1 & 14.6 \\
\hline Yes, high intensity & 13.3 & 12.7 \\
\hline \multicolumn{3}{|l|}{ Blood collection information } \\
\hline Median (range) gestational age of blood sample $<22 \mathrm{wk}$ (wk) & $10.4(4.4-21.0)$ & $10.1(5.1-19.0)$ \\
\hline Median (range) gestational age of blood sample at delivery (wk) & $39.7(23.7-42.0)$ & $39.0(26.6-41.3)$ \\
\hline
\end{tabular}




\section{TABLE 2}

Association between maternal vitamin D status at $<22 \mathrm{wk}$ gestation and preeclampsia diagnosis

\begin{tabular}{|c|c|c|c|}
\hline & Non-preeclamptic controls $(n=216)$ & Preeclampsia $(n=49)$ & $P$ value \\
\hline \multicolumn{4}{|l|}{ Maternal serum at $<22$ wk gestation } \\
\hline Adjusted geometric mean $25(\mathrm{OH}) \mathrm{D}^{a}[\mathrm{nmol} /$ liter $(95 \% \mathrm{CI})]$ & $53.1(47.1-59.9)$ & $45.4(38.6-53.4)$ & 0.01 \\
\hline \multicolumn{4}{|l|}{ Vitamin D status $(\%)$} \\
\hline $25(\mathrm{OH}) \mathrm{D}<37.5 \mathrm{nmol} / \mathrm{liter}$ & 15.7 & 28.6 & 0.08 \\
\hline 25(OH)D 37.5-75 nmol/liter & 50.0 & 46.9 & \\
\hline $25(\mathrm{OH}) \mathrm{D}>75 \mathrm{nmol} / \mathrm{liter}$ & 34.3 & 24.5 & \\
\hline
\end{tabular}

${ }^{a}$ Adjusted for maternal race/ethnicity, prepregnancy body mass index, education, season, and sample gestational age. 
TABLE 3

Association between preeclampsia diagnosis and neonatal vitamin D status

\begin{tabular}{|c|c|c|c|}
\hline & $\begin{array}{l}\text { Neonates of non- } \\
\text { preeclamptic } \\
\text { pregnancies }(n=164)\end{array}$ & $\begin{array}{l}\text { Neonates of preeclamptic } \\
\text { pregnancies }(n=40)\end{array}$ & $P$ value \\
\hline \multicolumn{4}{|l|}{ Cord serum } \\
\hline Adjusted geometric mean $25(\mathrm{OH}) \mathrm{D}^{a}[\mathrm{nmol} / \mathrm{liter}(95 \% \mathrm{CI})]$ & $50.3(43.6-58.1)$ & $39.2(32.0-47.9)$ & 0.001 \\
\hline \multicolumn{4}{|l|}{ Vitamin D status (\%) } \\
\hline $25(\mathrm{OH}) \mathrm{D}<37.5 \mathrm{nmol} / \mathrm{liter}$ & 20.7 & 37.5 & $<0.05$ \\
\hline $25(\mathrm{OH}) \mathrm{D} 37.5-75 \mathrm{nmol} / \mathrm{liter}$ & 44.5 & 42.5 & \\
\hline $25(\mathrm{OH}) \mathrm{D}>75 \mathrm{nmol} / \mathrm{liter}$ & 34.8 & 20.0 & \\
\hline $\begin{array}{l}\text { Adjusted }{ }^{a} \text { risk ratio: } 25(\mathrm{OH}) \mathrm{D}<37.5 \mathrm{nmol} / / \mathrm{liter} v s .237 .5 \mathrm{nmol} / \mathrm{liter} \\
(95 \% \mathrm{CI})\end{array}$ & 1.0 (referent) & $2.2(1.2-4.1)$ & $<0.01$ \\
\hline
\end{tabular}

${ }^{a}$ Adjusted for maternal race/ethnicity, prepregnancy body mass index, education, season, and sample gestational age. 